\title{
RAFAEL ARCE Y JUAN JOSÉ SAER: EL TRABAJO DE LA FELICIDAD
}

Sobre Rafael Arce. Juan José Saer: la felicidad de la novela. Santa Fe: UNL, 2015. 208 pp.

María Soledad Nivoli

CEPE - UNR

\section{La felicidad de la lectura}

“...si escribí este ensayo fue porque no encontraba en la crítica nada, o casi nada, que hablara de mi experiencia de lectura de Saer" (p. 8).

“...leer se ha vuelto la experiencia no de una ausencia de sentido (que sería igualmente un sentido: el absurdo), sino de una ausencia a secas, de la presencia de una ausencia"

El ensayo de Arce trabaja para restituir la serie de enigmas que jalonaron su experiencia de lectura: lee, cuenta y transmite la seguridad del trabajador-artesano, de aquél que ha comprobado la resistencia de los materiales, que ha padecido su inaccesibilidad y que ha ensayado cada una de las posibilidades de someterlos a ciertos fines, porque ha tenido la fortuna de ir a dar al taller del 'buen maestro' y de aprender a ser el 'buen discípulo'.

Se trata de una inteligente reconstrucción del trabajo de elaboración de la escritura saereana y de un ingenioso 
mecanismo de fabricación de hipótesis, que, sin embargo, no le ahorra a su propio lector la fortuna del trabajo. En efecto, la narración de Arce es amable: se deja querer porque quiere, se deja jugar porque no le ahorra al lector los desafíos del juego, se deja leer porque no enseña lo que es la lectura, simplemente la ejercita, la muestra. En ese sentido, es un escritor ejemplar. gesticula y urde, habilitando la réplica.

Si se nos permitiera hablar de cierta 'disposición pulsional' a la que constriñe su ensayo, sería precisamente la de urdir, pero en un sentido desplazado de los que habitualmente significan esta acción. Sabemos que, por un lado, urdir alude a tejer, a la combinación de la realización del recorrido de la trama con la tensión de la urdimbre. Por otro, refiere al diseño de un plan, generalmente malévolo, que ofrece un plus de goce a su mentor por la ganancia narcisista derivada del supuesto de que, en su despliegue y ejecución, se demostrarían las dotes geniales de su artífice. Arce orienta el esfuerzo de su ensayo -el 'onus' del argumento, como diría Taylor (1996)- a liberarse y liberar del espejismo: restituye con su libro ese mundo en el que todos urden y todos se equivocan, en el que ni los planes se estructuran según un maquiavelismo escolar ni triunfan o fracasan de modo ostensible. Su ensayo sabe y hace saber que por más inteligencia que haya, por más manejo de la técnica, artificiosidad, sagacidad, construcción y resolución de enigmas planificados, la trampa aparece siempre, en los lugares más insospechados, solidificándose de diversas maneras. Urdir, entonces, sería más bien trabajar para destituir la 'síntesis coagulada' en la que se cifra una presencia (la presencia de la tradición crítica, la presencia de los polos opuestos de las series complementarias) restituyendo la ausencia y con ella, la felicidad. Se trata de urdir una obra como 'desobramiento' (traducción del déscuvrement blanchotiano), trabajar para renunciar, trabajar para restituir el desobrar de la propia obra, 
trabajar por haber sido trabajado y forjar un trabajo para hacer trabajar.

\title{
El esfuerzo del desobramiento y el lugar de la novela
}

\author{
"Para Juan Melero y Lú Martínez: Debemos renunciar a \\ conocer a aquellos a quienes algo especial nos une” (p. 4). \\ “...descoagular el objeto Saer como institución literaria y \\ devolverle su déscuvrement, es decir, su experiencia literaria \\ (que a mí me gusta llamar novelesca)" (p. 20).
}

La renuncia a la que exhorta Arce en su dedicatoria, y que apunta al corazón de la relación amorosa con los amigos, también es el grito de batalla de su escritura. Hijo de la renuncia a conocer la obra de Juan José Saer, a la que algo -su propia experiencia de lectura- lo une de manera especial, este ensayo es, no obstante, la prueba de su 'triunfo', en el seno de un plan imposible. Y este triunfo del ensayo se revela en dos sentidos: por un lado, en el sentido de haberse arrancado de lo oscuro, de lo indiscernible, de lo indistinto, esgrimiendo el arma del desobramiento y orientándose, no hacia lo claro y distinto, sino más bien hacia la restitución de opacidades; y, por otro, en el sentido de haberse esforzado en construir un lugar para la crítica que no desdeñara los límites de la experiencia.

El plan imposible de Arce consiste en urdir un aparato crítico desde el corazón de la institución universitaria, en diálogo fluido y amoroso con las instituciones de la crítica y a partir del trabajo atento con los lugares comunes que estas producen. Este aparato crítico trabajaría para producir un efecto de restitución de la experiencia artística, al mismo tiempo 
que indicaría la necedad de su propio funcionamiento. La riqueza de este plan se cifra en la capacidad que demuestra: la de estar instalado en una zona intermedia entre el 'mundo de la crítica' y sus otros (notoriamente, la filosofía), ofreciendo su testimonio acerca de las posibles imbricaciones. Arce entreteje con delicadeza y por absoluta necesidad, su devenir testimonial con la materia del pensamiento filosófico presocrático, alemán y francés. En ningún momento la filosofía está concebida como ornato, nunca está utilizada como medio para su fin. La filosofía únicamente es convocada cuando tiene algo para decir acerca de esa experiencia que se detalla, y generalmente eso que tiene para decir oficia de clave para un acceso posible. Nunca es arena tirada a los ojos, nunca es cortina de humo. Arce contiene y se abstiene del impulso y del exceso 'filosofante' porque su interés no es rellenar sino vaciar, en la medida en que este vaciamiento apunte a la restitución de la experiencia de una ausencia, es decir, a la experiencia de la felicidad.

Sostiene la tesis de que en esta experiencia, la novela -tal como la ejercita la escritura saereana- cumple un papel fundamental. En efecto, como comprueba a lo largo de su ensayo, la novela se sustrae constantemente a la identificación yendo "...hacia sí misma saliéndose de sí misma”, es huésped de las imágenes disonantes, "...vuelve experimentable el aura de un mundo en desaparición, restituye la materialidad de las cosas volviendo sensibles las palabras" (p.18) y, sobre todo, obliga a asumir su 'contradicción productiva' (p.41), poniendo en funcionamiento un modo de preguntar desidentificador, que vuelve sospechosos los deslindes del mundo y hace vacilar las personificaciones del narrador. La novela, entonces, no como género, no como tipo, ni como clase: la novela como "...experiencia de lo que rodea, lo que va encerrando, merodeando, acechando" (p.43). 


\section{Las pistas de las series suplementarias}

El ejercicio de desobramiento que practica el libro de Arce, se sostiene en parte en la construcción de lo que llamaríamos 'series suplementarias', productos híbridos a medio camino entre la categoría freudiana de 'series complementarias' (Freud, 1997) y el uso lacaniano del adjetivo 'suplementario' (Lacan, 1992). A nuestro parecer, estos constructos acompasan el esquema reflexivo de Arce de tal manera que resulta posible resistir positivamente, a partir de ellos, a la tentación sintética del esquema dialéctico, tanto en su versión más escolarizada como en sus transcripciones más sofisticadas. Estas series suplementarias van señalando los puntos culminantes del trabajo del ensayo, produciendo cada vez la sensación simultánea de que algo se ha podido concluir y de que algo, necesariamente, tiene que recomenzar.

Sumariamente, nos interesaría distinguir y destacar algunas de estas series que, la mayoría de las veces, les permiten al autor de este ensayo y a sus lectores el acceso a la felicidad del desobramiento:

- La serie de la temporalidad de la novela, en la que la novela feliz saereana, que propone pensar el acaecer de la historia y las modalidades de su producción, interrumpe el espacio continuo bosquejado por el polo de la novela épica del siglo XIX, en la que el pasado determina el presente y el presente, al futuro, y el polo de la novela vanguardista del siglo $\mathrm{XX}$, en la que el presente determina el pasado, lo construye.

- La serie de la interpretación, en la que la imbricación, el contagio, el desobramiento y el desmantelamiento, 
interrumpen el procedimiento continuo diseñado entre el polo de la clarificación psiquiátrica, la verosimilitud y el régimen óptico de la luz, (imperios de la 'interioridad') y el polo de la imposibilidad y renuncia a toda clarificación (pura 'exterioridad').

- La serie del narrador, en la que la voz fenomenal interrumpe el continuo que va desde el polo del paternalismo (narrador-padre muerto) hasta el polo del parricidio (narrador- hijo, padre asesinado).

- La serie de la lectura, en la que la lectura antirrealista interrumpe el continuo esbozado entre el polo de la lectura realista y el polo de la lectura formalista.

- La serie del tiempo, en la que el éxtasis o las 'migaja de eternidad' interrumpen el continuo espacial entre el polo del tiempo como promesa, lo no cumplido y el polo del tiempo definido, lo cumplido.

- La serie de la visibilidad, en la que lo borroso interrumpe el régimen que va desde el polo de lo nítido al de lo opaco.

- La serie de la inteligibilidad, en la que el rumor y la voz difusa, interrumpen el continuo delimitado por el polo de la voz articulada y por el polo del sonido indiferenciado.

- La serie de la pertenencia, en la que la experiencia nómade del 'exotista estricto' interrumpe el continuo identitario tramado entre el polo del cosmopolitismo y el europeísmo y el polo del americanismo.

- La serie de los mundos, en la que la que el 'mundo pasta' interrumpe el continuo que se despliega entre el polo del 
mundo inaccesible, de la cosa en sí y el polo del mundo de lo ya-visto, lo ya-vivido, lo ya-oído.

- La serie del recuerdo, en la que el contacto de lo habiendosido y la aparición de una ausencia que llena, interrumpe el continuo bosquejado por el polo de la 'realidad del pasado' y el polo de la 'irrealidad de la memoria'.

Estas series funcionan, en el ensayo de Arce, como un espectro que interrumpe la continuidad de los polos opuestos solidificados, estandarizados o coagulados, gracias a una opción que de ningún modo podía estar contendida entre las alternativas polarizadas de la serie. La apuesta es a mostrar la posibilidad de resistir la lógica de la identidad sin caer en la trampa de la mera inversión, ensayando más bien la operación de la cuña, de la apertura de un continuo en un punto exacto en el que se logra hacerlo estallar.

\section{Referencias Bibliográficas}

Freud, S. (1997). "Conferencias de introducción al psicoanálisis". Obras Completas, Tomo XVI. Buenos Aires: Amorrortu.

Lacan, J. (1992). "Del Goce" y "Dios y el goce de La mujer". El Seminario XX Aún. Barcelona: Paidós

Taylor, Ch. (1996). Las fuentes del yo. Barcelona: Paidós. 